\title{
The Future of Yoruba Indigeneous Knowledge: Acquisition, Preservation and Transmission
}

\author{
Alarape, A. A. Ph.D ${ }^{1}$, Obadiora, A. J. Ph.D ${ }^{2}$, Omoba, F. A. Ph.D ${ }^{3}$ \\ ${ }^{1}$ Department of Educational Technology and Library Studies, Obafemi Awolowo University, Ile-Ife, Nigeria \\ ${ }^{2}$ Department of Arts and Social Science Education, Obafemi Awolowo University, Ile-Ife, Nigeria \\ ${ }^{3}$ Hezekiah Oluwasanmi Library, Obafemi Awolowo University, Ile-Ife, Nigeria
}

\begin{abstract}
This study investigates Yoruba Indigenous knowledge (IK) mode of acquisition, storage access, transmission and identify the revitalizing role of knowledge management (KM) principles on preservation of Yoruba indigenous knowledge. This research project is anchored in Smith's (1999) anti-colonial and African/Black feminist research methodologies because researchers are allowed to effectively engage the research objectives and the research questions. Face-to-face interviews were primary source of data. Researchers interviewed a diverse group of custodians of Yoruba IK and at least one of their children. While 8 participants agreed to participate in this research, in the end there were five custodians of different Yoruba IK that were separately interviewed. Each interview session lapses between 45-60 minutes and was digitally recorded and took place in person. Findings from research shows that Yoruba indigenous knowledge finds application and relevance in all spheres of human endeavor ranging from indigenous knowledge in medicine, crafts, bids making, manufacturing, drums making, drum playing, technology to manufacturing. The paper concluded that KM principles when applied to Yoruba IK could help to revitalize it and make it accessible to whosoever is interested in them. The research recommends that efforts and policy should be in place to compensate and protect the interest of the authors and ownership of Yoruba IK who are willing to decentralize their knowledge to encourage them to part with such IK.
\end{abstract}

\section{INTRODUCTION}

$\mathrm{T}$ he Yorubas are people whose major homeland is Southwestern Nigeria as one of the major ethnic groups in Africa. They have a history of highly sophisticated sociocultural and political systems. Like other ethnic groups in Africa, the Yorubas have an impressive system of indigenous Knowledge (IK). Indigenous knowledge (IK) is defined as a unique cumulative body of knowledge generated and evolved over time and possessed by people belonging to a particular geographic area enabling them to benefit from their natural resources (Guchteneire, Krukkert \& Liebenstein, 1999; Kaniki \& Mphahlele, 2002; Sen, 2005). IK is unique to a particular geographic location and is passed down from generation to generation. IK can be differentiated from Western scientific or modern knowledge in that the latter is developed and generated by research institutions, universities and private businesses (Agrawal, 1995; Kaniki \& Mphahlele, 2002).
Indigenous Knowledge is developed outside the formal education system, it does not necessarily operate within formal organisations and is mainly transferred by word of mouth (Guchteneire, Krukkert \& Liebenstein, 1999; Kaniki \& Mphahlele, 2002), practice, observation and indoctrination. Indigenous knowledge has been defined as a cumulative body of knowledge generated and evolved over time, representing generations of creative thought and actions within individual societies in an ecosystem of continuous residence, in an effort to cope with an ever- changing agro-ecological and socioeconomic environment. Terms like "traditional", "local", "community" and "rural people's knowledge" are used interchangeably with IK. Tharakan (2017) submitted that IK is the sum total of knowledge and skills possessed by people belonging to a particular geographic area, which enables them to benefit from their natural environment. Such knowledge and skills are shared over generations, and each new generation adds and adapts in response to changing circumstances and environmental conditions. However, still there is a grave risk that much indigenous knowledge is being lost and, along with it, valuable knowledge about ways of living sustainably both ecologically and socially (Okem. \& Odindo 2020). The value of indigenous knowledge is not only limited to agriculture, environment and biodiversity. It has an immense value in education, medicine, and so on. It leads to the development of a whole person in a dynamic family and community context. It incorporated principles of holism, integration, respect for the spiritual and natural world order, and the balance. On an individual scale, it encompassed total preparation of the total person for living a total life. The indigenous healing system follows a holistic approach. It is interdisciplinary and combines knowledge of botany, toxicology, chemical physics, biochemistry, and psychology. Indigenous medical practitioners tackle prevention as well as therapy, perceiving illness and healing holistically. Neglect of affective learning has contributed to escalating crime, drug dependency, pornography, and family/social breakdown in the West.

The Alaafin of Oyo, Oba Lamidi Adeyemi III in 2019 in his speech while declaring open a three-day international conference tagged, 'The Yoruba Nation and Politics Since the 19th Century' held in honour of Prof Joseph Adebowale Atanda at the Olabisi Onabanjo University (OOU), AgoIwoye, Ogun State stated that: 
"The Yoruba indigenous knowledge finds application and relevance in all spheres of human endeavour and forms the basis of development. A careful study of the Yoruba intellectual traditions would reveal the extent and in-depth of the Yoruba system of knowledge, which if properly studied would reveal an uncommon commitment to inquiry, research, investigation and functional application of knowledge in solving human existential problems. Alaafin further added that a perspective understanding and appreciation of developments in Yorubaland since 19th century would no doubt put the race in a better stead to negotiate from the point of advantage and strength and to preserve the legacies of the forebears. The monarch implored Yoruba scholars at the event to go beyond the limited requirements of paper presentation and be moved by a patriotic zeal to proffer solutions to its possibilities of going into extinction"

Just like other indigenous communities in the world, Yorubas are experiencing an erosion of IK as a result of slavery, mass migration to more developed countries, the influence of westernization, religion interferences, colonization, the First and Second World War, and modernization within the communities. The Yoruba older generations that have direct contact with the IK have almost gone and the remnants are already reaching retirement age while the younger Yoruba generations are being influenced by the pressures of modernization. Indigenous knowledge is often marginalized by society, therefore there is an urgent need to share, transfer and distribute this indigenous knowledge from older to younger generations so that its culture and traditions survive and prosper.

Owing to oral tradition, as well as introduction of new technologies, the preservation and utilization of Yoruba IK are at risk. For instance, it is not uncommon to see some piece of Yoruba IK being introduced as a modern idea, and then transferred across the borders without recognising and compensating the originators of the intellectual ideas. The majority of indigenous knowledge comes in the form of tacit knowledge, making it difficult to explain and transfer to younger generations without personal experience. This makes it hard for older Yoruba generations to show and explain to younger generations how to carry out certain customs and traditions especially if they do not live within the Yoruba territory where this IK resides. However, there is a grave risk that much indigenous knowledge is being lost as well as valuable knowledge about ways of living sustainably both ecologically and socially (Okem \& Odindo 2020). It is crystal clear that, if this knowledge goes to extinction, the survival of Yoruba kingdom, customs, belief and traditions is at serious risk. This is where knowledge management becomes more relevant. Consequently, it is important to undertake a study that delves deeply into the topic "revitalizing Yoruba indigenous knowledge through the application of knowledge management principles.
What is Knowledge Management (KM)? Knowledge management $(\mathrm{KM})$ is defined as the identification, optimisation and active management of intellectual assets, either in the form of explicit knowledge held in artifacts or as tacit knowledge possessed by individuals or communities". It could also be the optimisation of explicit knowledge achieved by consolidation and by making the artefacts available. KM is a body of methods, tools, techniques and values through which organisations can acquire, develop, measure, distribute and provide a return on their intellectual assets. Botha \&Van Rooyen (2000) defines knowledge management simply as the collection of processes that govern the creation, dissemination and utilisation of knowledge insight and experiences to fulfill organizational objectives. These definitions emphasise processes of finding, capturing, sharing and exploiting the available knowledge and information for the success of one's organisation over its competitors.

\section{Knowledge Management (Km) Processes and Approaches}

The principles and processes of knowledge management are highlighted by various authors. For example, Hussinki, Kianto, Vanhala, \&; Ritala (2017) posit three approaches to organisational KM as the mechanistic, cultural or behavioural, and systematic. Serrat (2017) identify the following as the core processes of $\mathrm{KM}$, which also guide its principles: knowledge identification; knowledge acquisition; knowledge development; knowledge sharing and distribution; knowledge utilization and knowledge retention. Other authorities of KM have referred to three kinds of approaches to effect knowledge management, namely, the mechanistic, cultural/behavioural and systematic approaches.

The mechanistic approach to KM focuses on the application of technology and associated resources as tools for facilitating access to information, and helps organisations achieve more with less. The cultural or behavioural approach, on the other hand, emphasises innovation and creativity, which are important for learning organisations. Introduction of new ways of doing things, new experiences that force organisations and communities to adopt a holistic view of their relationships with the environment influences community and organisational culture. The systematic approach uses systems thinking, which incorporates all aspects of $\mathrm{KM}$ to ensure continuous evaluation and a sustainable process. This requires the recognition and utilisation of the various cross-disciplines to develop KM systems and processes. Olubiyi (2019) for example, states that knowledge sharing is the essence of how we bring innovations to change the way the world works and lives. The key issue of course, is to identify the factors that motivate people within an organisation or community to share their intellectual assets. A learning community and organisation build collaborative relationships in order to draw strength from the diverse knowledge, experience, capabilities and ways of doing things that people and communities in general have and use. 
Davenport (1998) identifies ten principles that govern or guide KM processes. These also reflect some of the issues other scholars have raised about KM. Although many definitions of KM emphasise formal organisations, businesses and profits, they do not exclude the management of other forms of knowledge, including IK within the traditional communities where IK is often applied. Serrat (2017) uses a metaphor of an ecological community to define a $\mathrm{KM}$ community. In KM, a community of practice is defined as an interdependent group of people inhabiting the same information space, interacting with each other through resources and other relationships. He identifies three elements that are necessary to develop such communities. These are a clear identity of the community and what it stands for; a sense of belonging and attachment among members of the community; and the concept of self and non-self, that is a shared sense of who and what the parts of the community lie within it and what lies outside. This definition of the KM community of practice and the elements seems to cover the ethos and philosophies of traditional societies or communities and the IK within these communities.

Knowledge as an asset must be identified, captured, while value is added to it with investment of resources required. Knowledge management is an expensive process, because it involves knowledge capture and adding value through editing, repackaging and so on. It also involves developing knowledge categorization through processes such as classification, and developing and applying IT infrastructure for storage and distribution. Knowledge management of IK of Yoruba involves educating people about the techniques of creating, sharing and using knowledge within and outside their community or organisation. No one is ready to sponsor the process of managing the IK of Yoruba because there are alternatives to all the IK at crude level in advanced form from developed nations.

Identification of IK is done through travelling from one place to the other in order to know who and who are doing different things to make life confortable for the inhabitant of the community. For example, when a village is visited, the people in charge of security, health, administration, education, crafts, economy and law enforcement will be identified. The people will be captured and value will be added to the information to be retrieved from them. The whole process attracts a huge amount of money, which makes it difficult to access. The effective management of knowledge requires a hybrid of solutions involving people and technology. The phrase "knowledge is power" has become more of a reality today than in the past.

Knowledge is associated with power, money and success. Whoever has the know-how for doing something better is bound to trade that knowledge for profit, recognition or simply respect. Therefore, managing knowledge is highly political because it involves determining who has access to and can utilise and derive benefits from the valuable knowledge resources. All the people with IK in Yoruba land are in the remote area or not in the limelight. It is only very few educated among them that are known or recorgnised.

The custodians of IK are powerless poor and not successful. They are only contented with what they are doing. For example, the government launched a search for drug to cure COVID-19 in Abuja, many herbalists gathered with their herbs, while four of them were chosen to have passed the test of National Agency for Food and Drug Administration and Control (NAFDAC). For over nine months nothing was heard again. Those with power and money could pick on any of the drugs and reproduce it for sale. The IK custodians have knowledge but no money and no power because knowledge has become political in the land.

Like every resource in an organisation, knowledge must be managed, therefore, KM requires knowledge managers to manage key resources in organisations to facilitate their generation, distribution and use. The IK of Yoruba have no manager because everyone horde the information in their area of specialization, thereby making it difficult for others to access. If not appropriately managed, resources can be misused and thus depleted. Collecting and categorising knowledge, establishing knowledge-oriented technology infrastructure and monitoring the use of such knowledge are some of the tasks that KM managers should perform. Related to this is the facilitation of the creation, distribution and use of knowledge by members of a community.

A key element of $\mathrm{KM}$ is knowledge sharing within a given environment or community. However, in order to share knowledge effectively for the benefit of the community, and its members, and to facilitate productivity, knowledge maps must be generated. Maps of knowledge assets show where and how particular knowledge assets are stored in the community. Communities benefit more by knowledge mapping and by marketing the available knowledge in a transparent manner, than by operating in hierarchical fashion which is the order of the day in a typical Yoruba setting.

Although KM emphasises sharing knowledge, sharing and using knowledge are often unnatural acts. Knowledge is often kept in order to preserve power and prestige. Communities have to identify and use effective motivators and motivating techniques to facilitate knowledge sharing. At the same time, custodian of the identified knowledge and generators of knowledge must be assured that they will be appropriately compensated, rewarded and/or recognised for their knowledge. Communities should also invest in developing knowledge sharing and distribution techniques and best practices, which imply that application of Information Communication Technologies (ICT) in knowledge networks is essential in modern society.

Another important KM principle identified by Davenport (1998) is that KM means improving knowledge work processes. The knowledge generation must be facilitated, 
utilised and transferred by putting in place appropriate policies, resources and facilities. However, improving knowledge work processes may not necessarily be as simple and straightforward as it sounds. It is complex and requires financial, human and material resources, which are not available due to poor or no funding from the necessary quarter.

Information and knowledge are not useful unless they are applied to specific situations. Though access to knowledge is important but it is not sufficient. As Davenport (1998) argues, access to knowledge is only the beginning. To be useful and profitable, knowledge must be applied. Explicit knowledge which is contained in patents is always available and accessible, but in order to become useful it must be applied. This issue is even more complex with respect to tacit knowledge. A member of community may have access to another person who has the know-how for a particular task.

However, if the person with the knowhow does not share or use his or her knowledge to accomplish a task, then the knowledge is irrelevant. The mode of sharing is through apprenticeship which is made difficult by exorbitant charges from the master and inhuman treatment that scares people from learning any form of IK. Knowledge generation, its utilisation and transfer are necessary because new problems and situations arise and require new solutions. The whole purpose of scientific research is discovering new and adding to old knowledge in order to deal with new phenomena. The information needs of people change with time, circumstance and environment. Therefore, information provided even for similar needs must suit the situation and circumstance. Need for new knowledge and its application changes with time, since there is no stage when knowledge is fully managed in Yoruba IK.

One of the main questions that may be asked with respect to international and even national KM initiatives for IK is the protection of intellectual property rights. In dealing with intellectual property, one of the key issues is the identification of the originator or owner of the know-how. A community that develops and applies particular IK as their culture generally owns the IK.

Another key principle of $\mathrm{KM}$ is that it requires a knowledge contract. Human beings are naturally competitive creatures and strive to improve their living conditions. Kaniki (2001) argues, however, that in spite of their natural competitive tendencies, humans "have learnt that the forces of competition must be balanced with an equal measure of cooperation. It is ascertained that money, time, effort and other resources invested in the creation and/or development of intellectual property or know-how (knowledge) must be recognised and rewarded. The reward is lacking in the Yoruba IK, the custodians of this IK are neither acknowledged nor compensated and when compensated, it is very low beyond expectation. The non-rewarding acts make the people in custody of Yoruba IK to decline in divulging necessary information.

Ahmed (2017) points out that communities, national governments and international communities are responsible for protecting individuals' rights and property. Legal frameworks, rules and regulations, such as copyright laws, patent laws, trademarks and trade laws, have been put in place. They not only encourage competition and cooperation, but also protect individuals' and government property.

In addition to legal frameworks and laws, human beings depend on conventional practice, moral values, judgement and obligations or ethics in their interaction with one another and in the protection of their rights and those of the community. Therefore, it is important to identify who owns what and has the right to use an individual's knowledge. The judicial system in Nigeria is too expensive for the custodian of IK to afford, thereby making it difficult for them to enjoy intellectual property right.

An important step in recognising the usefulness of anything in society and thus warranting the allocation of limited resources to it is, firstly, raising awareness about the issue. The work of international IK centres established in different parts of the world have promoted IK and made those who initially have been skeptical about IK appreciate its role in dealing with human development issues. Initiatives such as the Interim Committee on Indigenous Knowledge Systems in Southern Africa, which came together in 1995 to promote the mapping, conservation and application of IK within the southern African region, can be traced to the collective work of these international centres.

Hence, communities know which practices are more common in some regions or areas, and which are less common or not found at all in others. In the process of instituting intellectual property rights and/or mapping IK, it is possible for each community to identify and specify the IK that belongs to it. The individual creativity and invention will have to be recognised and protected. The difficulty in linking IK to particular communities may be related to tacit IK. It is often not easy, and in fact generally impossible, to ascribe particular practices related to the work of these persons to particular communities.

A number of international conventions and agreements, like the Berne Convention on Copyright and the Agreement on Trade-Related Aspects of Intellectual Property Rights (TRIPS), as well as international patent laws, attempt to protect intellectual property from piracy and abuse internationally. There are also national intellectual property laws and regulations. However, as Quiroz (1994) indicates, the existing intellectual property rights agreements do not give full and proper recognition to the rights of indigenous and local communities to their own knowledge, innovations and practices. Where such property rights and agreements cover 
indigenous communities and their IK, enforcement of the law or sanctions requires policing and advocacy.

Often such advocacy comes in the form of a community itself acting as the custodian of the IK and, at the same time, as the watchdog for any transgressions. It means that a body or persons must take the responsibility of making sure that a community's IK is not abused. In spite of the fact that details of this decision or judgement were not included in the short newspaper article, it would not be far from the truth to speculate that the process must have taken a long time to resolve. It must also have involved local and international lawyers who will also benefit from this pay-out!

IK systems should be brought into the mainstream of knowledge in order to establish their place within the larger body of knowledge. The socio-economic potential of IK should be considered, as well as the non-socio-economic values such as the impact of IK on lifestyles and the ways in which societies are run. The image collection represents the rich IK of the region, comprising antique and modern art, photographic prints, negatives, slides, transparencies and book illustrations. Museum documentation is also enriched with images of ethnographic objects, including Zulu pots, beadwork, carved sticks and items of traditional dress.

The digitisation project at the Campbell Collections employs a three-tiered access system to protect the intellectual property that resides in these rare and often unique collections. The documentation of rich artefactual collections is enriched with a digital image of indigenous art, ethnographic objects and historic photographs. Low-resolution images are prepared in two sizes for presentation on the Web. This allows for identification of the subject matter and meets the expectation that "everything on the Web is free". Medium-resolution copies are made available to bona fide researchers at a minimal cost designed to cover expenses. Providing access to research resources is ultimately the Campbell Collections' objective. Copies of high-resolution archival master images are made available commercially on request, following a discreet investigation of the intended purpose, around which a business model has been constructed. The business model also protects intellectual property by employing a differentiated pricing structure for local and international clients. The pricing structure further differentiates between standard and educational publications, and single or multiple broadcasts in one country or worldwide.

In this way, the Campbell Collections aim to make their IK resources readily available locally for education and research. Peters (2001) points out that the Collections have taken cognisance of the fact that, through reformatting in a digital format, the cultural heritage of the South is made vulnerable to commercial exploitation by people in the North, thus reinforcing the digital divide. Instead, the Campbell Collections have taken advantage of the poor exchange rate of the South African rand to other currencies like the American dollar and pound sterling, to generate a market-related income to finance its ongoing digitisation programmes.

It is clear that a number of KM activities and initiatives are in place or are taking shape internationally, nationally and even regionally. However, it is important to look at the local or community levels and ask the question: How applicable are $\mathrm{KM}$ principles in managing IK at the (indigenous) local community level? Related to this general question are specific questions like: To what extent is knowledge mapping, "recording", retention and sharing done in and among local communities? Some of the KM principles can be applied to manage certain aspects of IK and owing to the nature of IK not all of it can (or should) be managed like scientific knowledge. For example, in local communities there are individuals who act as custodians of IK. In traditional communities, intellectual property is protected through trust and not necessarily through legal frameworks.

Moreover, it is clear from the study of traditional societies that knowledge sharing and learning within systematic and sophisticated manner, as Thakadu (1998) concludes. However, it is recognised that in the interaction of local or traditional communities with modern communities (and, in fact, the global community) there is a need to apply a number of principles for managing IK in order to preserve, utilise effectively and protect it. IK maps are essential for serving as guides to what type of knowledge is available and where it is available. Knowledge audits need to be conducted to enable structuring of knowledge, not only for better access but also for identification of ownership. However, there would be interaction between traditional/local communities, the government and knowledge experts. Most importantly, there must be mutual trust and a working together for the common good among the stakeholders. Owners of intellectual property, whether individually or collectively, must be recognized and rewarded accordingly.

\section{Objectives}

The objectives this research intends to achieve are to:

- Identify different forms of indigenous knowledge

- Determine the mode of acquisition, storage access and development of indigenous knowledge

- Identify the revitalisation role of knowledge management on indigenous knowledge

\section{Research Questions}

The Research Questions this research intends to answer are:

- What are the different types of indigenous knowledge identified among Yorubas?

- What are the importance of Yoruba IK identified to individual, family and the entire community and the nation at large?

- How is the indigenous knowledge acquired, documented, and processed? 
- How can knowledge management principles be used to revitalize indigenous knowledge among Yorubas?

\section{METHODOLOGY}

This research project is anchored in an anti-colonial framework that holds Indigenous Knowledge to be essential decolonizing tools for liberation (Dei, 2001) methodologies because it allows researchers to effectively achieve the learning objectives and the research questions. This project is therefore anchored in Smith's (1999) anti-colonial methodology of privileging Indigenous worldviews or cosmologies. Indigenous methodologies are often a mix of existing methodological approaches and indigenous practices. The mix reflects the training of indigenous researchers which continues to be within the academy, and the parameters and commonsense understandings of research which govern how indigenous communities and researchers define their activities (1999:143).

Face-to-face interviews were the primary instrument of data collection and were vital to this research. Principal custodian of Yoruba IK were interviewed and at least one of their children. While eight (8) Yoruba IK custodian agreed to participate in this research, in the end there were five different families with a total of 14 participants that were individually interviewed. A small sample size of 14 was ideal for gathering in-depth, richly textured and more nuanced experiential information through face-to-face interviews. The small number of participants is more conducive for a study that engages spirituality because it is a subject that is more likely to be richer and flourish in a personal/intimate one-on-one setting such as an interview, where privacy and confidentiality are both respected and protected. Each interview ranged from 45-60 minutes. All interviews were digitally recorded and took place in person.

\section{RESULTS AND DISCUSSION OF FINDINGS}

Four research questions were raised and were discussed base on the research objectives

Research Question 1: What are the types of Indigenous Knowledge Identified among Yorubas?

The result of the interview revealed that Yoruba indigenous knowledge finds application and relevance in all spheres of human endeavor ranging from agriculture, environment and biodiversity, medicine, technology, crafts, arts, education that forms the basis of development. It incorporated principles of holism, integration, respect for the spiritual and natural world order, and the balance. On an individual scale, it encompassed total preparation of the total person for living a total life. The indigenous healing system follows a holistic approach. It is interdisciplinary and combines knowledge of botany, toxicology, chemical physics, biochemistry, and psychology. Indigenous medical practitioners tackle prevention as well as therapy, perceiving illness and healing holistically. Neglect of affective learning has contributed to escalating crime, drug dependency, pornography, and family/social breakdown in the West.

Beliefs of the community are examples of where Indigenous knowledge can be reflected, based on its religion and/or culture, for example, ancestral worship and the belief of custodians of IK that the ancestors are the community's intermediaries between man and God. Many communities believe that ancestors can communicate with individuals. Therefore, there are dos and don'ts in each community that guides the activities that takes place.

Indigenous knowledge in medicine is also practiced and very much consulted till date for treatment of several ailments in which herbs are used as traditional medicine for treating ailments and also as preventative medicine. For a community to survive and flourish, elementary community necessities such as clean water and air, safe and healthy food, renewable energy, accessible and affordable healthcare, relevant and topical education as well as information and technology needs, must be satisfactorily met.

Often, it is the indigenous knowledge of these communities that is the basis for their technological development. Contribution of IK to development depends on identification of needs, after identifying relevant and applicable needs, a broad and diverse spectrum of appropriate technologies can be called upon as a resource base, allowing communities to selfselect and focus on those areas that are of critical immediate need for the community. This drawing from IK for the development will promote and enhance sustainability practices and principles within the community.

Yoruba IK in human resources management is another aspect of indigenous knowledge, where decisive development and leadership roles are determined by kinship. The head of the community could command resources within the community to assist those who were not able to look after themselves. If a person was found to be in dire straits, but not simply because of laziness or lack of effort, the chief or village headman would call communal labour. Strong, healthy men and women in the village would be identified to build houses for those who could not do this on their own. The chief or head of the community not only controls the physical resources, but is also the custodian of the valuable knowledge resources available within the community. He or she is therefore able to call upon those persons who may have special powers, such as rainmaking or medicinal know-how, to deal with a particular situation as necessary. Traditional leaders had the authority to make final decisions.

The Yoruba traditional methods of education were practiced through initiation schools or apprenticeship. Through Yoruba traditional methods of education, young community members learn about tradition itself and craft. They learn about various beliefs and about having respect for oneself and others, particularly for elders. Through observing the behavioural and seasonal migration of prey and the tell-tale signs of weather 
changes, for example, the youths learn about the connectivity of the environment and humanity. A body of knowledge is continually being accumulated and preserved to be shared with successive generations. Although the scientific reality of this belief may be difficult to prove, it serves another purpose, namely that of security.

One of the main areas in which Yoruba IK was found to be very rich is that of farming practices and agriculture (Mavhura \& Mushure, 2019). Yoruba IK was found to be very rich is that of farming practices and agriculture Examples of local soil classifications and herbal medicines have been tried, tested and seen to work even in the scientific arena. Indigenous people practice intercropping, that is, they plant different crops in the same field. For instance, maize or corn and beans are intercropped to retain soil nutrients. When the land lies idle for a season or so, the soil is covered with ash to protect it from unwanted insects.

Yoruba IK interviewees also agreed that various food production, preservation and storage systems have been developed and effectively applied in Yoruba traditional societies. They concluded that usually food production appear at particular times of the year and are therefore harvested during specific seasons. However, they can be preserved for many months or years simply by boiling them in water, sometimes salted and sundried. A similar method is used for preserving African spinach. The use of Yoruba IK in the brewing of beer is also well developed among traditional communities. Generally, IK in food processing and preservation is highly developed in many communities.

Among the Yoruba IK interviewees, all of them agreed on the existence of well developed, decorative and utility products which are made from wood, clay, beads, fabrics, soil and other materials. The technologies and techniques used in each community are often unique and highly sophisticated. Special types of clay are used for making specific types of pots. Decorations on the pots may convey particular messages and/or indicate the specific use of the pot. Owing to its oral tradition, as well as the introduction of new technologies, the preservation and utilisation of IK are at risk. For instance, it is not uncommon to see some piece of IK being introduced as a modern idea, and then transferred across the borders without recognition of and compensation for the originators of the intellectual ideas. This is where knowledge management becomes more relevant.

Question 2: What are the importance of Yoruba IK identified to individual, family and the entire community and the nation at large?

Most of the custodians of the earlier itemized indigenous knowledge practitioners agreed unanimously that their IK secures the family of the practitioners, the community where it is practiced and the nation at large. Most of the custodians of the indigenous knowledge agreed that IK they acquired is an asset that should be managed both effectively and efficiently. This is the more reason why they charge any intending learner heavily before accepting such to have the Nitti gritty of the knowledge. Some IK practitioners do not even allow apprenticeship from outside their extended families (A kii fi idi ebiti rebete han omode, bi bee ko eku a po loja) This is in line with the principle of Knowledge management that is based on the idea that knowledge is an asset that should be managed (just as capital assets are managed). Explicitly stating that knowledge is a valued asset makes it clear that teams are expected to manage and protect knowledge.

Research Question 3: How do you document, and processes the indigenous knowledge?

Most of the custodians of the indigenous knowledge agreed that Yoruba IK they acquired is a traditional knowledge and it is being transferred orally for years now. The only time documentation may be allowed is maybe when someone comes for consultation and the methods or processes used have to be recorded. Some said that there is no original documentation of the records yet. Respondents claimed that all the major ingredients of IK are transferred orally and those things that are recorded were not the primary things to be documented and kept for future use. The findings from the interview guide show that the Yoruba IK is individualized, and not centralized as that individuals have a tendency to horde knowledge in their own makeshift repositories thereby paving way for easy extinction as the death of the custodians of such IK can bring an end to such IK.

Question 4: How can knowledge management principles are used to revitalize indigenous knowledge among Yorubas'?

One of the biggest problems that Yoruba indigenous knowledge programs face is islands of knowledge. To solve this problem, Yoruba IK should be stored in a central repository so as to encourage teams and users to create their own knowledge spaces and stimulate ease of access to such IK. KM principles ensure that everything goes into one central repository. Your knowledge repository (e.g. IK content management system)

Knowledge is Retained: As shown by the result from the interview guide, the IK mode of retention is by passing it from one generation to the other. For instance there is a family that is well known to have traditional knowledge of bone setting (orthopedics) ditto all other forms of indigenous knowledge. The practice of this knowledge can only be learnt or done by the member of this family. There is no organized set of health check criteria for indigenous knowledge. The moment a given set of the family refused to imbibe this traditions, there is move towards extinction of the IK. KM principles that ensure everything Knowledge is retained according to organizational retention policies. Retention may be managed with a set of societal check criteria for knowledge. For example, knowledge that is old, unreferenced and unused may be pruned. 
Knowledge is Quality Controlled: Yoruba IK is individualized, and not centralized in that individuals have a tendency to horde knowledge in their own makeshift repositories. KM principle ensure that everything goes into one central repository.to facilitate its quality control. However, the custodians of IK are not ready to relinquish their knowledge for improvement and quality control thereby impeding its development to the world standard. The principle of KM which says Knowledge is Quality Controlled usually set the expectation that knowledge is quality controlled. For example, quality guidelines may state that IK ownership (who contributed to knowledge) be captured and patented for adequate compensation that will secure economic benefit of its authorship.

Knowledge is decentralized: Most knowledge management responsibilities lie with those teams closest to the knowledge. It's a bad idea to centralize all knowledge management processes. Most of the Yoruba IK management responsibilities lie with those families closest to the knowledge. The Yoruba IK are managed centrally from the small family group who resides closely to the source of the knowledge. It is not good enough to centralize all knowledge management processes as this will minimize the effectiveness and efficiency of such knowledge. Applying the principle of $\mathrm{KM}$ which implies that knowledge is decentralized will make the Yoruba IK spread, and people more aware of it thereby making its application more efficient.

Knowledge is Social: The finding from this research revealed that most of the Yoruba IK Knowledge is kept on a shelf which has actually reduced its value, development and efficiency. Most of the Yoruba IK Knowledge are not communicated and socialized for fear of stolen it away thereby taken the ownership and economic benefit attached to it away. To revitalize most of the Yoruba IK Knowledge their creation, assessment, improvement and use of such IK should be made to follow social process. Knowing full well that knowledge that sits on a shelf has no value. The value of knowledge depends on communication and socialization. The creation, assessment, improvement and use of knowledge is largely a social process. A primary goal of knowledge management is to facilitate the sharing of knowledge. Encourage your organization to share (e.g. lunch and learn sessions).

Knowledge is Accessible: The finding from this research revealed that most of the Yoruba IK are not as valuable as they should because they are not accessible to a wide audience. Privacy and confidentiality prevent most custodians of Yoruba IK from sharing their knowledge. However, it's important to set the expectation that a valid reason is required to restrict access. Applying $\mathrm{KM}$ principle that says Knowledge is more valuable when it's accessible to a wide audience. However, it's important to set the expectation that a valid reason is required to restrict access. The concept of accessibility also addresses access to knowledge for individuals with disabilities or special needs.

Knowledge is secured: Most of the respondents asserted that the Yoruba IK they have or holding on to is valuable as it is their source of livelihood. If this indigenous knowledge is their most valuable information, it is critical that information security best practices be followed for these indigenous knowledge management processes and tools.

\section{CONCLUSION}

The findings from the study revealed that IK is not: Secured, Accessible, Decentralized, Retained, communicated and horde knowledge in their own makeshift repositories to facilitate its quality control. Yoruba IK is still at the crude level and could easily go into extinction without remembering it's ever existed. Knowledge management could salvage the Yoruba IK if early introduced with the cooperation of the custodians of Yoruba IK.

\section{RECOMMENDATION}

Knowledge management processes should be adopted to salvage the Yoruba indigenous knowledge. The leaders and philanthropists should be approached for sponsorship because of the expensive attribute that goes with it.

\section{REFERENCES}

[1] Agrawal, A. (1995) Indigenous and Scientific Knowledge: Some Critical Comments Antropologi Indonesia 3(3). DOI: 10.7454/ai.v0i55.3331

[2] Ahmed, A. (2017). How do the top 40 business schools in the UK understand, teach and implement knowledge management in their teaching? World Journal of Science Technology and Sustainability. 14(23), 111-134.

[3] Botha, M. \& Van Rooyen, L. 2000. Knowledge management. Meta-info Bulletin, 9(3): 28-36.

[4] Davenport, T.H. 1998. Some principles of knowledge management. http://www.bus.utexas.edu/kman/kmprin.htm

[5] Hussinki, H., Kianto, A., Vanhala, M. \&; Ritala, P. (2017) Assessing the universality of knowledge management practices. Journal of knowledge management.21 (6), 1596 - 1621

[6] Kaniki Andrew M. M.E. Kutu Mphahlele (2013) Indigenous knowledge for the benefit of all: Can knowledge management principles be used effectively? South African Journal of Libraries and Information Science 68(1)

[7] Kaniki, A.M. 2001. The use and abuse of information and the business ethics thereof. Paper presented at the SABINET Client's Conference, Fossil fuel - B2B (back to basics). Cathedral Peak Hotel, Drakensberg, South Africa, 30-31 August. [Online]. http://www.sabinet.co.za/conference/

[8] Mavhura, E., \&Mushure, S. (2019) Forest and wild life resource conservation efforts based on indigenous knowledge: the case of Nharira community in Chikomba District, Zimbabwe. Forest policy and economics 105. 83-90.

[9] Mavhura, E., Manyena, S.B., Collins, A.E., Manatsa, D., 2013. Indigenous knowledge, coping strategies and resilience to floods in Muzarabani, Zimbabwe. Int. J. DisasterRisk Reduction 5. https://doi.org/10.1016/j.ijdrr.2013.07.001

[10] Guchteneire, P. de, Krukkert, I.J., Liebenstein, G. von (1999) Best practices on indigenous knowledge, Centre for International Research and Advisory Networks, NUFFIC; The Hague, The Netherlands 
[11] Okem, A. E. \&Odindo, A. O. (2020) Indigenous Knowledge and Acceptability of Treated Effluent in AgricultureSustainability 2020, 12(21), 9304; https://doi.org/10.3390/su12219304

[12] Olubiyi, T. O. (2019). Knowledge management practices and family business profitability: evidence from Lagos state Nigeria. Global Journal of Management and Business Research. 19(11).

[13] Peters, D. (2001). The Campbell Collections digitization project. E-mail message to A.M. Kaniki, 13 November

[14] Sefa Dei, G. J. (2001). Rescuing Theory: Anti-Racism and Inclusive Education. Race, Gender \& Class, 8 (1): 139 - 161.

[15] Sen, A (2005) The Argumentative Indian: Writings on Indian Culture, History and Identity. London: Allen Lane.

[16] Serrat, O. (2017). How would you motivate interest in knowledge management? Retrieved

from

DOI:
[17] Smith, L. T. (1999) Decolonizing Methodologies. Research and Indigenous Peoples London, UK: Zed Books

[18] Thakadu, O.T. 1998. Indigenous wildlife management knowledge systems and their role in facilitating community-based wildlife management projects in Botswana. Unpublished MSc (Environment and Development). Pietermaritzburg: University of Natal

[19] Tharakan, J. (2017). Indigenous Knowledge Systems for Appropriate Technology Development, Indigenous People, Purushothaman Venkatesan, IntechOpen, DOI: 10.5772/intechopen.69889. Available from: https://www.intechopen.com/books/indigenouspeople/indigenous-knowledge-systems-for-appropriatetechnology-development. 